\title{
Morphology dependence on anions in hydrothermal synthesis of $\mathrm{CO}_{3} \mathrm{O}_{4}$
}

\author{
Wei-Min Zhang ${ }^{*}$, Meng Chen and Yao-Quan Jiang
}

\begin{abstract}
One-dimensional (1D) nanostructures of $\mathrm{CO}_{3} \mathrm{O}_{4}$ were synthesized via a mild hydrothermal route. The results of XRD, IR, and TEM revealed a phase transformation was accompanied by the replacement of $\mathrm{NO}_{3}{ }^{-}$with $\mathrm{CO}_{3}{ }^{2-}$ throughout the hydrothermal process. The symmetric types and amount of $\mathrm{NO}_{3}{ }^{-}$and $\mathrm{CO}_{3}{ }^{2-}$ intercalated between the brucite layers played an important role in the formation of nanowires from the hydrothermal system. The amount of $\mathrm{CO}_{3}{ }^{2-}$ increased as the hydrothermal reaction proceeded. The substitution of $\mathrm{CO}_{3}{ }^{2-}$ for $\mathrm{NO}_{3}{ }^{-}$led to a variation of interlayer forces thus resulted in the instability of intralayer interactions. Therefore, a shape transformation from sheets to wires occurred. Upon calcination, the shapes of precursors were preserved, and $1 \mathrm{D}$ nanostructures of $\mathrm{CO}_{3} \mathrm{O}_{4}$ resulted.
\end{abstract}

Keywords: One-dimensional nanostructures; Hydrothermal synthesis; Anion

\section{Introduction}

The hydrothermal system simulating the mineral formation is adapted to synthesize one dimensional (1D) nanostructured materials with high crystallinity. 1D nanostructures of $\mathrm{Co}_{3} \mathrm{O}_{4}$ have aroused great interest due to its mixed valence states [1-3]. The 1D nanostructures could be achieved by many preparative strategies [4-8]. $\mathrm{Co}_{3} \mathrm{O}_{4}$ exhibited potential application in a wide variety of fields, such as battery materials [9-11], catalysis [12,13], and magnetic materials $[4,8,14]$. It is now commonly known that the properties of nanomaterials strongly depend on the shape of particles, which is a dominating factor to their ultimate performance and applications [8,15-18]. In this paper, a hydrothermal pathway was carried out to investigate the controlled formation of $1 \mathrm{D}$ $\mathrm{Co}_{3} \mathrm{O}_{4}$. The hydrothermal procedure was monitored combinationally by the techniques of XRD, TEM, and FTIR in order to deeply understand the function of anions in the formation of 1D nanostructures.

\section{Experimental}

The typical preparation of $1 \mathrm{D} \mathrm{Co}_{3} \mathrm{O}_{4}$ is described as follows: $5 \times 10^{-3} \mathrm{~mol} \mathrm{Co}\left(\mathrm{NO}_{3}\right)_{2} \cdot 6 \mathrm{H}_{2} \mathrm{O}$ and $1.25 \times 10^{-3} \mathrm{~mol}$ hexamethylenetetramine (HMT) were added into the 10 $\mathrm{mL} 5 \times 10^{-3} \mathrm{~mol} / \mathrm{L}$ sodium dodecylsulfate aqueous solution

\footnotetext{
* Correspondence: chm_zhangwm@ujn.edu.cn

School of Chemistry and Chemical Engineering, University of Jinan, Jiwei road, Jinan 250022, China
}

under ultrasonication. The solution was then transferred into the Teflon-lined stainless steel autoclave for hydrothermal treatment at $160^{\circ} \mathrm{C}$ for $6 \mathrm{~h}$. The hydrothermally obtained anion-intercalated cobalt hydroxides were rinsed with deionized water and anhydrous alcohol three times and suffered calcination in air at $500^{\circ} \mathrm{C}$ for $6 \mathrm{~h}$ to produce the final products.

Thermogravimetric (TG) analysis and differential thermal analysis (DTA) were carried out in air for the precursor of $\mathrm{Co}_{3} \mathrm{O}_{4}$ with a Rigaku Thermplus TG8120 (Rigaku, Shibuya-ku, Japan) with a heating rate of $5^{\circ} \mathrm{C} / \mathrm{min}$. Powder $\mathrm{X}$-ray diffraction (XRD) patterns of the samples were measured using a Rigaku $\gamma \mathrm{A}$ Mini diffractometer with $\mathrm{Cu} \mathrm{K \alpha}$ radiation $(\lambda=0.154178 \mathrm{~nm})$. The morphologies were observed by transmission electron microscopy (TEM) (obtained using a JEM-100CXII electron microscope (JEOL, Akishima-shi, Japan)) and scanning electron microscopy (SEM) (carried out by JSM-6700F). Fourier transform infrared spectra (FT-IR) of samples formed in $\mathrm{KBr}$ platelets were recorded with an Avatar 370 FT-IR spectrometer (ThermoNicolet, Waltham, MA, USA) in the range of 400 to $4000 / \mathrm{cm}$ to investigate the crystalline form of products.

\section{Findings}

The TGA-DTA analysis for precursors suggests two steps of losing weight: the weight loss below $100^{\circ} \mathrm{C}$ is mainly due to dehydration of physically absorbed water, while the decomposition of $\mathrm{NO}_{3}{ }^{-}$and $\mathrm{CO}_{3}{ }^{2-}$ ions,

\section{Springer}


together with the dehydration of $\mathrm{OH}$ groups between brucite layers of $\mathrm{Co}(\mathrm{OH})_{2}$ during which occurs a simultaneous conversion into spinel $\mathrm{Co}_{3} \mathrm{O}_{4}$, contribute to the greater weight loss observed between $200^{\circ} \mathrm{C}$ and $500^{\circ} \mathrm{C}$. Correspondingly, two endothermic peaks are shown in the DTA curve. The precursors have transformed completely into $\mathrm{Co}_{3} \mathrm{O}_{4}$ above $500^{\circ} \mathrm{C}$ (Figure 1).

The precondition to obtain the 1D nanostructures of $\mathrm{Co}_{3} \mathrm{O}_{4}$ is synthesizing the $1 \mathrm{D}$ precursor. The molar ratio of starting reactants was found as an important parameter; therefore, some experiments were carried out by varying both $\mathrm{Co}\left(\mathrm{NO}_{3}\right)_{2}$ and HMT amounts. Only within a very narrow range of the molar ratio of $\left[\mathrm{Co}^{2+}\right]$ to $\left[\left(\mathrm{CH}_{2}\right)_{6} \mathrm{~N}_{4}\right]$ $(2: 1 \sim 4: 1)$, the wirelike precursors of cobalt basic nitrate carbonate could be obtained. The precursors and final products calcined at $500^{\circ} \mathrm{C}$ were further characterized by TEM and SEM techniques. A typical TEM image of Figure 2a reveals that the precursors display almost perfect 1D morphologies with widths about $100 \mathrm{~nm}$. The lengths are estimated about 3 to $10 \mu \mathrm{m}$. Apparently, the aspect ratios of these 1D nanostructures are notably large. In addition, the precursors have proved the copiousness in quantity, and the uniformity in size distribution. The calcined products exhibit rough surfaces, as shown in Figure $2 \mathrm{~b}$, c, suggesting the polycrystalline feature. The energy dispersive spectrum (EDS) of the selected field, which is white framed in Figure 2c, was measured for the $500^{\circ} \mathrm{C}$ calcined products, and the result displayed in Figure $2 \mathrm{~d}$ indicates the molar ratio of $\mathrm{Co} / \mathrm{O}$ equal to 0.72 , in good agreement with the theoretic value of $\mathrm{Co}_{3} \mathrm{O}_{4}$.

As shown in Figure 3, XRD, TEM, and IR techniques were employed combinationally in order to gain some insights on the function of anions in the formation of $1 \mathrm{D} \mathrm{Co}_{3} \mathrm{O}_{4}$.

Reaction time dependence of XRD patterns for precursors exhibited a phase transformation from initial metastable

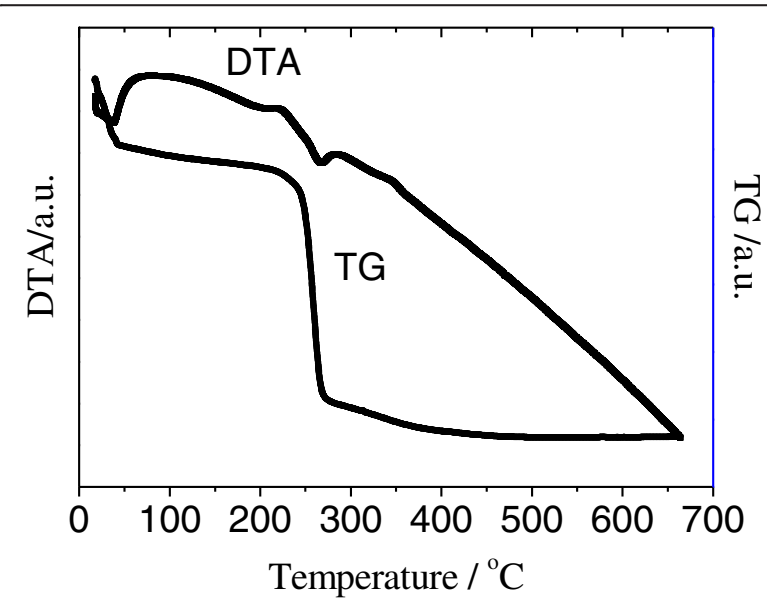

Figure 1 Thermogravimetric analysis (TGA) and differential thermal analysis (DTA) curves of precursors obtained hydrothermally $\left(180^{\circ} \mathrm{C}, 4 \mathrm{~h}\right)$.
$\alpha-\mathrm{Co}(\mathrm{OH})_{2}$ to the thermodynamically stable phase, which showed a similarity with $\mathrm{Co}\left(\mathrm{CO}_{3}\right)_{0.35} \mathrm{Cl}_{0.2}(\mathrm{OH})_{1.1} \cdot 0.74 \mathrm{H}_{2} \mathrm{O}$, implying that $\mathrm{NO}_{3}{ }^{-}$ions occupied the same position as $\mathrm{Cl}^{-}$ ions in the $\mathrm{NO}_{3}{ }^{-}$intercalated cobalt carbonate hydroxide.

The phase transformations were accompanied by the morphology alterations. As shown in Figure 3, nanosheets were obtained after $20 \mathrm{~min}$ of hydrothermal treatment. When the holding time was prolonged to $1 \mathrm{~h}, 1 \mathrm{D}$ nanostructures with the length of $2 \mu \mathrm{m}$ coexisted with the nanosheets. After the holding time increased above $2 \mathrm{~h}$, only nanowires were obtained.

FT-IR technique is an effective way to investigate the kind of anions intercalated between the $\mathrm{Co}(\mathrm{OH})_{2}$ layers. The precursor $\alpha-\mathrm{Co}(\mathrm{OH})_{2}$ taken from solution at $20 \mathrm{~min}$ has a large interlayer space, designated literally as a prehydrotalcite-like phase as confirmed by IR and XRD. Water bending mode is also found at $1,601 / \mathrm{cm}$, about $30 / \mathrm{cm}$ red shift due to strong interactions with the interlayer anions of $\mathrm{NO}_{3}{ }^{-}$and/or $\mathrm{CO}_{3}{ }^{2-}$. In agreement with the structural assignment, absorption peaks at 1,384 and $839 / \mathrm{cm}\left(v_{3}\right.$ and $v_{2}$ vibration modes of $\mathrm{NO}_{3}{ }^{-}$with $\mathrm{D}_{3 \mathrm{~h}}$ symmetry) indicate that a large number of $\mathrm{NO}_{3}{ }^{-}$anions are included $[19,20]$. With increasing the holding time, the intensity of the peak at $1,384 / \mathrm{cm}$ decreased obviously, and the $v_{2}$ vibrational modes appear at $830 / \mathrm{cm}$, apparently lower than $\mathrm{NO}_{3}{ }^{-}$with $\mathrm{D}_{3 \mathrm{~h}}$ symmetry, indicating an increment in the perturbation of the intercalated $\mathrm{NO}_{3}{ }^{-}$. Simultaneously, two peaks appear at 1,480 and $1,312 / \mathrm{cm}$, which can be assigned to symmetric vibrational mode $\left(v_{\mathrm{s}}\left(\mathrm{ONO}_{2}\right)\right)$ and asymmetric vibrations $\left(v_{\text {as }}\left(\mathrm{ONO}_{2}\right)\right)$ on monodentate nitrate, respectively. In addition, the appearance of a tiny peak at $1,312 / \mathrm{cm}$ suggests that the amount of $\mathrm{NO}_{3}^{-}$is significantly reduced $[19,21]$. The IR spectra for sample prepared after the holding time above $2 \mathrm{~h}$ shows two more absorptions at 1,506 and $1,035 / \mathrm{cm}$, which belong to the $v_{3}$ and $v_{1}$ vibrational modes of carbonate anions with $\mathrm{C}_{2 \mathrm{~V}}$ symmetry. Compared with the data from $\mathrm{Xu}$ and Zeng [20], the two absorptions exhibited blue and red shifts, respectively. The perturbation can be attributed to stronger electrostatic interactions between the divalent $\mathrm{CO}_{3}{ }^{2-}$ anions and the brucite-like sheets.

In summary, the probable procedure for the formation of $1 \mathrm{D} \mathrm{Co}_{3} \mathrm{O}_{4}$ could be described as follows: initially, a large amount of $\mathrm{NO}_{3}^{-}$ions intercalated between the brucite layers, adopting $\mathrm{D}_{3 \mathrm{~h}}$ symmetry. The amount of $\mathrm{CO}_{3}{ }^{2-}$ gradually produced by hydrolysis and oxidation of HMT increased, leading to the substitution for some of $\mathrm{NO}_{3}{ }^{-}$ ions and the alteration of symmetry from $D_{3 h}$ to $C_{2 v}$. Consequently, the modification of interlayer forces resulted in the instability of intralayer interactions, and the two-dimensional nanosheets eventually transformed to 1D nanostructures. The morphology was preserved in calcination to produce $1 \mathrm{D} \mathrm{Co}_{3} \mathrm{O}_{4}$. 

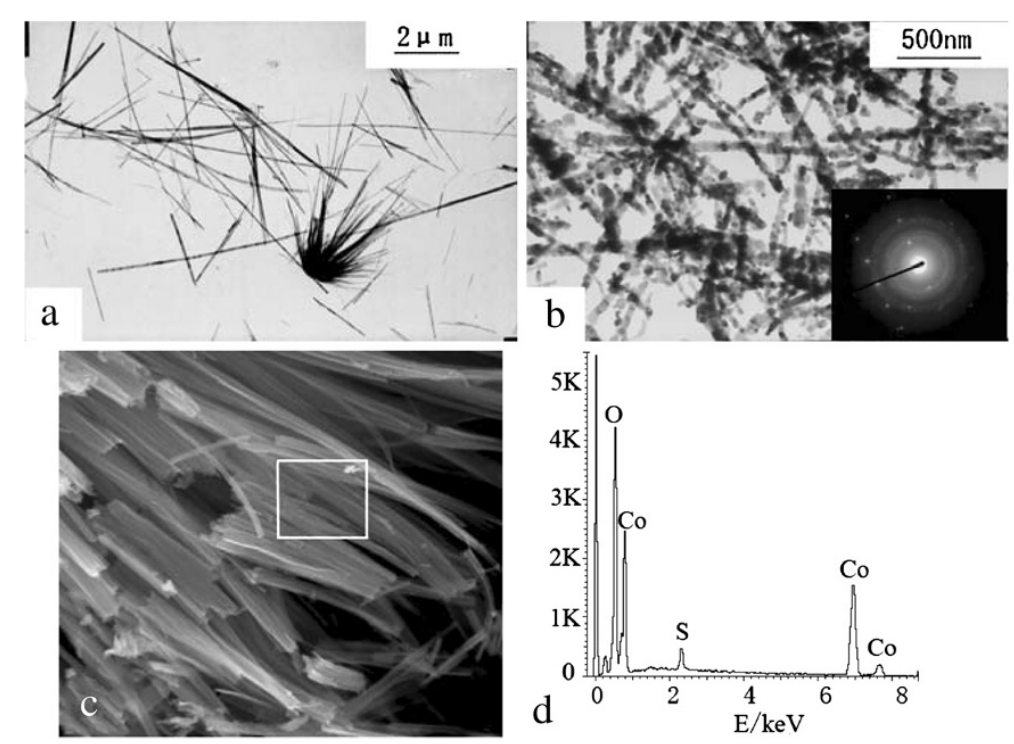

Figure 2 The morphology of the precursor (a), the calcined products (b and c), and EDS (d). SAED of the calcined products is inset in (b), and EDS results white framed in (c) are also exhibited in (d).
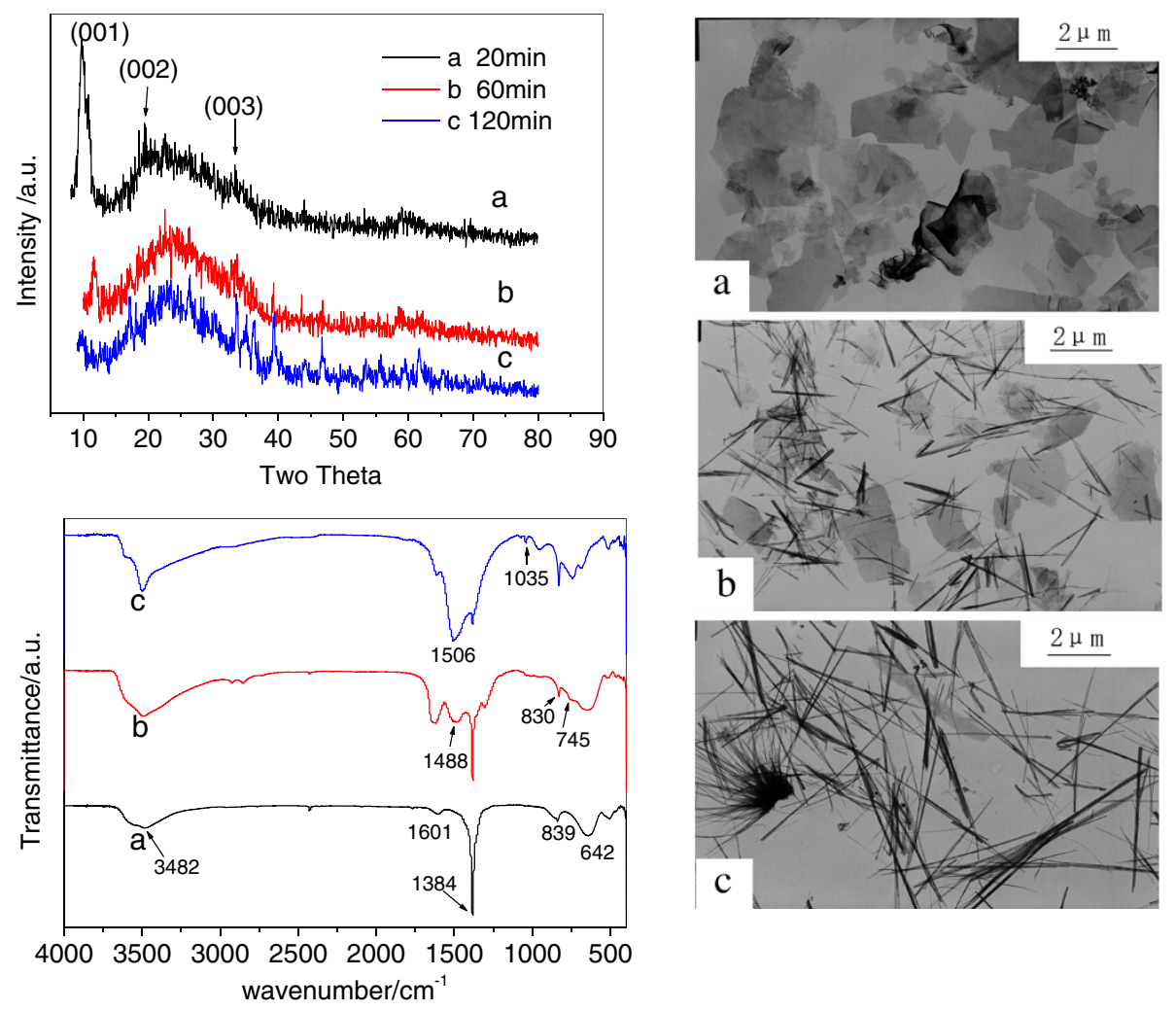

Figure 3 Temporal evolution of XRD patterns, TEM images, and IR spectrum. For precursors taken out of the autoclave at different stages of hydrothermal treatment: (a) 20, (b) 60, and (c) 120 min. 


\section{Competing interests}

The authors declare that they have no competing interests.

\section{Authors' contributions}

WMZ, as the corresponding author, instructed the other two authors to carry out the experiments and drafted the manuscript. MC synthesized the samples and contributed a lot in phase analysis of samples using techniques of XRD and TEM. YQJ provided his contributions in the IR analysis. All authors read and approved the final manuscript.

Received: 4 July 2012 Accepted: 30 April 2013

Published: 15 July 2013

\section{References}

1. Lakshmi, BB, Patrissi, CJ, Martin, CR: Sol-gel template synthesis of semiconductor oxide micro-and nanostructures. Chem. Mater. 9, 2544-2550 (1997)

2. Liu, $Y$, Wang, $G, X u, C$, et al.: Fabrication of $\mathrm{CO}_{3} \mathrm{O}_{4}$ nanorods by calcination of precursor powders prepared in a novel inverse microemulsion. Chem. Commun. 1486-1487 (2002)

3. Wang, D, Caruso, RA, Caruso, F: Synthesis of macroporous titania and inorganic composite materials from coated colloidal spheres - A novel route to tune pore morphology. Chem. Mater. 13, 364-371 (2001)

4. Meher, $\mathrm{SK}, \mathrm{Rao}, \mathrm{GR}$ : Ultra-layered $\mathrm{CO}_{3} \mathrm{O}_{4}$ for high performance supercapacitor applications. J. Phys. Chem. C 115, 25543-25556 (2011)

5. Wei, $C$, Nan, Z: Effects of experimental conditions on one-dimensional singlecrystal nanostructure of $\beta-\mathrm{FeOOH}$. Mater. Chem. Phys. 127, 220-226 (2011)

6. Chen, N, Huang, C, Yang, W, et al.: Growth control for architecture molecular conductor of low dimension nanostructures. J. Phys. Chem. C 114, 12982-12986 (2010)

7. Kar, S, Pal, BN, Chaudhuri, S, et al:: One-Dimensional ZnO nanostructure arrays: Synthesis and characterization. J. Phys. Chem. B 110, 4605-4611 (2006)

8. Wang, G, Shen, X, Horvat, J, et al:. Hydrothermal synthesis and optical, magnetic, and supercapacitance properties of nanoporous cobalt oxide nanorods. J. Phys. Chem. C 113, 4357-4361 (2009)

9. Wang, $\mathrm{B}$, Wang,, , Park, J, et al.: In situ synthesis of $\mathrm{CO}_{3} \mathrm{O}_{4} /$ graphene nanocomposite material for lithium-ion batteries and supercapacitors with high capacity and supercapacitance. J. Alloys Compd. 509, 7778-7783 (2011)

10. Yao, $X, X i n, X$, Zhang, $Y$, et al:: $\mathrm{CO}_{3} \mathrm{O}_{4}$ nanowires as high capacity anode materials for lithium ion batteries. J. Alloys Compd. 521, 95-100 (2012)

11. Li, L, Wang, $Y$, Wang, $Y$, et al.: Mesoporous nano- $\mathrm{CO}_{3} \mathrm{O}_{4}$ : A potential negative electrode material for alkaline secondary battery. J. Power. Sources 196, 10758-10761 (2011)

12. Cui, $Y$, Wen, $Z$, Sun, $\mathrm{S}$, et al.: Mesoporous $\mathrm{CO}_{3} \mathrm{O}_{4}$ with different porosities as catalysts for the lithium-oxygen cell. Solid State Ionics Solid State Ion. 225, 598-603 (2012)

13. Asano, $\mathrm{K}$, Ohnishi, $\mathrm{C}$, Iwamoto, $\mathrm{S}$, et al.: Potassium-doped $\mathrm{CO}_{3} \mathrm{O}_{4}$ catalyst for direct decomposition of $\mathrm{N}_{2} \mathrm{O}$. Appl. Catal. B 78, 242-249 (2008)

14. Nethravathi, $\mathrm{C}, \mathrm{Sen}, \mathrm{S}$, Ravishankar, $\mathrm{N}$, et al.: Ferrimagnetic nanogranular $\mathrm{Co}_{3} \mathrm{O}_{4}$ through solvothermal Decomposition of colloidally dispersed monolayers of a-cobalt hydroxide. J. Phys. Chem. B 109, 11468-11472 (2005)

15. Geng, B, Zhan, F, Fang, C, et al:. A facile coordination compound precursor route to controlled synthesis of $\mathrm{CO}_{3} \mathrm{O}_{4}$ nanostructures and their room-temperature gas sensing properties. J. Mater. Chem. 18, 4977-4984 (2008)

16. Jia, Z, Wang, $Q$, Ren, D, et al.: Fabrication of one-dimensional mesoporous $\mathrm{a}-\mathrm{Fe}_{2} \mathrm{O}_{3}$ nanostructure via self-sacrificial template and its enhanced $\mathrm{Cr}(\mathrm{VI})$ adsorption capacity. Appl. Surf. Sci. 264, 255-260 (2013)

17. Luo, Z, Yin, S, Wang, K, et al:. Synthesis of one-dimensional $\beta-\mathrm{Ni}(\mathrm{OH})_{2}$ nanostructure and their application as nonenzymatic glucose sensors. Mater. Chem. Phys. 132, 387-394 (2012)

18. Song, Q, John Zhang, Z: Shape control and associated magnetic properties of spinel cobalt ferrite nanocrystals. J. Am. Chem. Soc. 126, 6164-6168 (2004)

19. Xu, ZP, Zeng, HC: Interconversion of brucite-like and hydrotalcite-like phases in cobalt hydroxide compounds. Chem. Mater. 11, 67-74 (1999)
20. Xu, ZP, Zeng, HC: Thermal evolution of cobalt hydroxides: a comparative study of their various structural phases. J. Mater. Chem. 8, 2499-2506 (1998)

21. Schraml-Marth, M, Wokaun, A, Baikert, A: Surface structure of crystalline and amorphous chromia catalysts for the selective catalytic reduction of nitric oxide IV. Diffuse reflectance FTIR study of NO adsorption and reaction. J. Catal. 138, 306-321 (1992)

doi:10.1186/2228-5326-3-44

Cite this article as: Zhang et al.: Morphology dependence on anions in hydrothermal synthesis of $\mathrm{CO}_{3} \mathrm{O}_{4}$. International Nano Letters 2013 3:44.

\section{Submit your manuscript to a SpringerOpen ${ }^{\odot}$ journal and benefit from:}

- Convenient online submission

Rigorous peer review

- Immediate publication on acceptance

- Open access: articles freely available online

- High visibility within the field

- Retaining the copyright to your article

Submit your next manuscript at $>$ springeropen.com 